\title{
Relationship of Player Experience and Game Engagement in Battle Royale Games among Gamers in Davao City
}

\author{
Louie Jay M. Gilves ${ }^{1}$, Ron Angelo Quilario², Rizel Mae Atanoza ${ }^{3}$, Baby Joy Alameda Miano ${ }^{4}$, Jezriel Bajan ${ }^{5}$ \\ ${ }^{1,2,3,4}$ Bachelor of Science in Information Technology, Jose Maria College, Philippines \\ ${ }^{5}$ Faculty, Jose Maria College, Philippines
}

\begin{abstract}
A characteristic of multiplayer web-based games is that players may take whatever job they choose, collaborate with other sections to complete far more complex goals, and complete missions of a violent nature. Players may communicate online, form friendships, and arrange real or virtual resources [1]. This research aims to ascertain the connection between Player Experience and Game Engagement in Battle Royale Games among Davao City Gamers. To ascertain the degree of player experience and game engagement and ascertain if there is a statistically significant connection between those factors. The data collection process is conducted through questionnaires. It is based on two of the most frequently used scales: the Player Experience of Need Satisfaction (PENS) and the Game Experience Questionnaire (GEQ). Although both measures were created using a rational-theoretical approach, none has been subjected to formal factor analysis. Fifty (50) respondents from Davao City between the ages of 16 and 40 who are eligible for our research were chosen. The researchers utilized purposeful sampling to choose an example that is usually beneficial to the study goals to produce an example that may represent the community. The findings indicate that most video games remain tenacious in their quest for popularity and do not seem to have an end in sight. Real-life and the virtual world are gradually merging with virtual reality on the horizon and making inroads into more conventional settings. The research concluded by examining the elements of game playing experience that may improve people's competence, idea autonomy, and relatedness. The degree to which it is significant and how it connects with other factors.
\end{abstract}

Keywords: PUBG Game Experience and Engagement, Davao City

\section{INTRODUCTION}

$\mathrm{N}$ owadays, individuals play games through their smartphones. When Android was released, more game developers took advantage of the opportunity to profit by developing new games with high-quality visuals, stimulating people, particularly children and adolescents who own an Android smartphone or have one at home [1]. Thus, if kids are hooked to playing games with no time constraints, this will result in health issues such as eye difficulties, neck discomfort, backbone pain, and headaches. This research aims to ascertain the Player Experience of the PUBG game among adolescents in Davao City.
Online computer games first appeared in the 1990s and have grown in popularity and availability since then. The number of web-based games being played and the number of participants has exploded.

A characteristic of multiplayer web-based games is that players may take whatever job they choose, collaborate with other sections to complete far more complex goals, and complete missions of a violent nature. Players may communicate online, form companions, and arrange trades of real or virtual resources [2]. Engaging, intelligent, and continuing web-based games have developed into "killer apps" on the Internet. They are the primary reasons why a few teenagers spend hours playing these games regularly [3].

In any event, as the popularity of web-based games has grown, so have concerns about their excessive usage. The urgent extravagance in multiplayer online gaming is most prevalent within the age group of 13-25 years, with gaming abuse being more prevalent among young males than young women [4]. The rising trend of mass shootings has also been linked to excessive use of violent computer games, reviving debate about the possible adverse effects of violent computer games on children and adolescents [5]. Given youth's preponderance of online usage and web-based gaming, there is growing concern that a portion of Internet-using kids may engage in hazardous or habit-forming web behaviors when using and gaming on the web [6]. The World Health Organization (WHO) designated the proclivity and urge for computerized and video gaming as an emotional well-being issue in 2018 [7]. Additionally, web-based gaming enslavement is defined as an apparent social obsession characterized by excessive or frequent use of PC games or computer games that interfere with an individual's everyday life [14].

Recently, another gaming obsession, Player Unknown's Battlegrounds (PUBG), has gained widespread acclaim. It is a multiplayer shooter game in which 100 people compete in a 'battle royale,' with the last person or group remaining victorious [8]. The game may be played with either friends or strangers. The majority of players are reliant on this game and spend an excessive amount of energy playing it. Numerous children play this game, despite the fact that it is intended for people above sixteen due to the client connection and 
advanced purchases. According to a survey of gamers, $47 \%$ have played at least one very vicious game.

Vygotsky (1978) asserts that humans develop tools and are subsequently affected by those tools [8]. The Internet is the most complex instrument humanity has ever created, and as such, it has the potential to have a more significant artistic effect than any prior technology [11]. As is customary, new technology inspires fear and worry. For example, in the nineteenth century, "the telegraph allowed a young lady to continue a flirtation with a number of men on the wire, despite her father's wishes." [12]. Recent studies also show that games can be beneficial in educational activities and family interaction, such as in [22] and [23].

\section{METHODOLOGY}

\section{Research Design}

We present a conceptual model based on existing theories and previous empirical results that examines the variables influencing and affecting online gaming pleasure. As shown in our model, pleasure is strongly linked to the narrative, visuals, music, duration, and control of online games, and enjoyment predicts intention to play online games while allowing for the impacts of attitude and subjective norms on behavioral intention [13].

\section{Research Locale and Sampling}

The study will be conducted at Davao City, 8000 Davao del Sur. Fifty (50) respondents from Davao city will be selected. We will select participants were above the age of 16 that are applicable for our study. Our choice of selecting these fifty (50) participants will be ideal since they are the ones who could give us the best information regarding our research which is the Relationship of Player Experience and Game Engagement in Battle Royale Games Among Gamers in Davao City. We will select these participants according to their capability to provide relevant information and share their experience and game engagement in Battle Royale Games.

In this study, the researcher will select Fifty (50) PUBG gamers in Davao City. It now satisfies the standard least adequate example size for the correlational examination.

The researchers used the purposive sampling technique in choosing their participants regardless of their gender and age. Purposive sampling is a non-probability type of sampling that relies mainly on the researchers' judgment in choosing respondents. Unlike the various sampling techniques that can be used under probability sampling, the goal of purposive sampling is not to ramdomly select units from a population to create a sample to generalize from that sample to the population of interest.

Purposive sampling involves the researchers utilizing their insight to pick an example that is generally helpful to the study objectives. A purposive example's principal objective is to create an example that can be illustrative of the population.

\section{Data Collection Procedure}

The following procedures will be done to gather and present all the necessary data for the study:

Ask permission. A remarkable fraction of this study's data collection is through the virtual world. Ask a result; the researchers will need to ask permission from the selected respondents through messenger. The researchers must proceed only if their request gets approved and if they would be given permission to do so.

Distribution of survey questionnaires. We researchers create a questionnaire in google form, which we send to our participants through social media platforms. Once approved, the survey questionnaires shall then be sent to a messenger to the chosen respondents to answer. The respondents will be given enough time to answer the survey questionnaire.

Retrieval survey questionnaires. Once the respondents finish answering the survey questionnaires, survey questionnaires will then be retrieved. The answers and identity of the respondents will be taken care of in consideration with confidentiality and rules of ethics.

Tabulation, merging, analysis, and interpretation of data. The data that will be gathered throughout this study will be tabulated, organized, merged, and evaluated in line with the objectives of the study. The unbiased evaluation shall be done for the researchers to have extensive knowledge of the topic they are researching.

\section{Research Instrument}

Accurate player experience assessment is critical for comprehending the effects of videogame play, creating and producing compelling videogames, and successfully applying game design concepts in other areas. Numerous player experience surveys are accessible. However, empirical validation of the scales is often lacking or nonexistent.

The questionnaire is based on two widely used scales: the Player Experience of Need Satisfaction (PENS) and the Game Experience Questionnaire (GEQ). Both measures were created using a rational-theoretical approach; however, neither scale has been subjected to formal factor analysis, restricting our ability to assess the scales' empirical validity [15]. This was initially utilized in Ujjwal Dubey's study titled "Measuring Player Experience and Engagement Level in PlayerUnknown's Battlegrounds." [9].

The researchers provided comprehensive exploratory and confirmatory factor analyses of both scales using videogame player answers. The GEQ is supported in part (through a redesigned factor structure); the PENS is supported in a significant part (with a more minor revision of the factor structure) [10]. We provide recommendations for future study on the most effective usage of both scales. 


\section{Ethical Considerations}

The researchers conducted consent first to the participants before they could participate in this study. Several ethical issues had to be taken into consideration. The age of the participants was one of the main ethical issues [16]. The researchers had to make sure all the participants were above the age of 16, and any participants under this age must be allowed by a legal guardian. Confidentiality was another crucial ethical concern. To maintain anonymous participants were asked not to put their original name in any questionnaires. Additionally, participants were informed on the questionnaire that all data will be kept confidential.

Generally, studies that include contact with a human sample will have some ethical ramifications. Building trust with research participants is critical, which was accomplished by maintaining anonymity and responding confidently to all responses, carefully explaining the research process and data presentation, and providing as much information about the project and its objectives as possible without influencing responses. The researchers sought to respectfully research the participants and other human beings that the research process may influence.

\section{RESULTS AND DISCUSSIONS}

\section{Profile of the Respondents}

As shown in Table 1, there is several more or less 49 respondents in this study. Most of the respondents were age ranges from 16 to 30 years old. The highest percentage of respondents are in the age range of 21-23 years' old which is $46.9 \%$. Moreover, based on gender characteristics got $73.5 \%$ of the respondents were male and $26.5 \%$ remained female.

According to that the influence of gender, age, family race/ethnicity, and socioeconomic status on gameplay found males play video games more than females. Both sexes prefer different games, females dislike games with violent content, lacked meaningful social interaction, and had character. Regarding the length of game experience 18 respondents got $36.7 \%$ less than a year while the lowest percentage comes to the respondents who had 3-5 years' experience.

Table I: Frequency and Percentage Distribution of the Respondents Profile

\begin{tabular}{|c|c|c|}
\hline Characteristics (n=49) & Frequency & Percentage \\
\hline Age & 20 & 40.8 \\
16-20 years old & 23 & 46.9 \\
21-25 years old & 6 & 12.2 \\
26-30 years old & & \\
\hline Gender & 36 & 73.5 \\
Male & 13 & 26.5 \\
Female & & \\
& & \\
Length of Game & 14 & 28.6 \\
Experience & 18 & 36.7 \\
1-2 years & 8 & 16.3 \\
Less than 1 year & 9 & 18.4 \\
3-5 years & & \\
More than 5 years & & \\
&
\end{tabular}

\section{The Level of Player Experience Among the Gamers}

Table 2 shows the level of players' experience among the gamers and this is divided into three indicators that players felt competence during involvement in the game. The autonomy scale measures the degree to which respondents felt free, and perceived opportunities to do activities that interest them with striving. In-game relatedness, the size assesses the will to attach with others in a way that feels authentic and supportive. These findings show that the mean of the Level of the Player Experience in terms of competence is 3.92 with a standard deviation of .533 .

This means that the Level of the Player Experience in terms of competence is high. Additionally, for the next indicator tackles about the player experience autonomy is 4.31 with a standard deviation of .452. This means that the level of autonomy is very high. For the last indicator which is the relatedness of the level of player experience is 3.87 with a standard deviation of .493 , this means that that the relatedness of the players' game experience is high.

Table II: Mean and Standard Deviation Distribution of Respondents' Level of Player Experience Among the Gamers Descriptive Statistics

\begin{tabular}{|c|c|c|c|}
\hline Indicators & $\mathrm{N}$ & Mean & Std. Deviation \\
\hline Competence Mean & 50 & 3.3704 & .36167 \\
\hline Autonomy Mean & 50 & 4.31 & .59921 \\
\hline Relatedness Mean & 50 & 3.87 & .494 \\
\hline Overall & & 4.03 & .493 \\
\hline
\end{tabular}

\section{Level of the Game Engagement}

Level of the Game Engagement The mean level of the game engagement is 4.38 with a standard deviation of .402 . This means that the level of game engagement is very high. While there has been significant growth in game-based learning research in the past two decades. This is supported by the idea that games also offer an opportunity to explore new ideas and actions through the diversity of gameplay opportunities generated by communities of players.

Table III: Mean and Standard Distribution of Respondents' Level of Game Engagement

Descriptive Statistics

\begin{tabular}{|c|c|c|c|}
\hline Indicator & $\mathrm{N}$ & Mean & Std. Deviation \\
\hline Game Engagement & 50 & 4.38 & .402 \\
\hline
\end{tabular}

Significant Difference on the Level of Player Experience in Intervening Variables 
Table IV: Anova Distribution of Respondents' Significant Difference in Leve of Player Experience according to Age, Gender, Length of Game Experience

ANOVA (Between Groups)

\begin{tabular}{|c|c|c|c|c|c|c|}
\hline $\begin{array}{c}\text { Test } \\
\text { Variables } \\
\text { (ANOVA) }\end{array}$ & Level & Mean & SD & $\mathrm{F}$ & Sig. & Decision \\
\hline Age & $\begin{array}{c}16-20 \\
\text { years } \\
\text { old } \\
21-25 \\
\text { years } \\
\text { old } \\
\\
26-30 \\
\text { years } \\
\text { old }\end{array}$ & $\begin{array}{l}4.00 \\
4.11\end{array}$ & $\begin{array}{l}.297 \\
.398 \\
.681\end{array}$ & 1.103 & .340 & $\begin{array}{c}\text { Accept } \\
\text { Но }\end{array}$ \\
\hline Gender & $\begin{array}{c}\text { Male } \\
\text { Female }\end{array}$ & $\begin{array}{l}4.04 \\
4.03 \\
\end{array}$ & $\begin{array}{l}.389 \\
.453 \\
\end{array}$ & .010 & .922 & $\begin{array}{c}\text { Accept } \\
\text { Ho }\end{array}$ \\
\hline $\begin{array}{l}\text { Length of } \\
\text { Game } \\
\text { Experience }\end{array}$ & $\begin{array}{c}\text { Less } \\
\text { than } 1 \\
\text { year } \\
1-2 \\
\text { years } \\
3-5 \\
\text { years } \\
\text { More } \\
\text { than } \\
\text { five } \\
\text { years }\end{array}$ & $\begin{array}{l}4.01 \\
3.93 \\
4.13 \\
4.17\end{array}$ & $\begin{array}{l}.360 \\
.409\end{array}$ & .803 & .499 & $\begin{array}{c}\text { Accept } \\
\text { Но }\end{array}$ \\
\hline
\end{tabular}

Because the p-values of.340, 922, and.499 are more than 0.05 . We do not reject the null hypothesis. When players are classified according to their age, gender, and duration of gaming experience, there is no discernible variation in their degree of experience. The Player Experience of Need Satisfaction (PENS) metric evaluates gaming experiences for competence, autonomy, relatedness, intuitive controls, and presence/immersion. Additionally, this metric assesses the individual player experience by examining the interface between the player and the activity occurring inside the game environment and the extent to which the player's behavior and response to the game satisfy particular psychological requirements [17].

\section{Significant Difference on the Level of Game Engagement in Intervening Variables}

The table below shows the ANOVA Distribution of the respondents and its significant difference between the age, gender and the length of the game experience. It implies there that the decision must be accept the null hypothesis to its intervening variables. Since, $p$-values $.918, .954$ and $.426>$ 0.05 then we do not reject the null hypothesis. There is no significant difference on the level of game engagement when grouped according to age and gender and length of game experience.
This is reinforced by the fact that gaming involvement affects a variety of variables. For example, for individuals of any age or gender, it promotes the development of creativerelated abilities. It allows players to maintain a broad focus while participating in open-ended games. Positive reinforcement is provided via the feedback activities, which promotes autonomy and self-awareness [18].

Table V: Anova Distribution of Respondents' Significant Difference in Level of Game Engagement according to Age, Gender, Length of Game Experience

\section{ANOVA (Between Groups)}

\begin{tabular}{|c|c|c|c|c|c|c|}
\hline $\begin{array}{c}\text { Test } \\
\text { Variables } \\
\text { (ANOVA) }\end{array}$ & Level & Mean & SD & $\mathrm{F}$ & Sig. & Decision \\
\hline \multirow{3}{*}{ Age } & $16-20$ years old & 4.36 & .382 & \multirow{3}{*}{0.86} & \multirow{3}{*}{.918} & \multirow{3}{*}{$\begin{array}{c}\text { Accept } \\
\text { Ho }\end{array}$} \\
\hline & $21-25$ years old & 4.40 & .451 & & & \\
\hline & 26-30 years old & 4.34 & .309 & & & \\
\hline Gender & $\begin{array}{l}\text { Male } \\
\text { Female }\end{array}$ & $\begin{array}{l}4.38 \\
4.39 \\
\end{array}$ & $\begin{array}{l}.426 \\
.340 \\
\end{array}$ & .003 & 954 & $\begin{array}{c}\text { Accept } \\
\text { Ho }\end{array}$ \\
\hline \multirow{4}{*}{$\begin{array}{l}\text { Length of } \\
\text { Game } \\
\text { Experience }\end{array}$} & Less than 1 year & 4.44 & .359 & \multirow{4}{*}{.984} & \multirow{4}{*}{.426} & \multirow{4}{*}{$\begin{array}{c}\text { Accept } \\
\text { Ho }\end{array}$} \\
\hline & $1-2$ years & 4.37 & .482 & & & \\
\hline & $3-5$ years & 4.17 & .304 & & & \\
\hline & More than 5 years & 4.45 & .357 & & & \\
\hline
\end{tabular}

Relationship of Player Experience and Game Engagement

Table VI: Correlation Between Measures Correlations

\begin{tabular}{|c|c|c|c|c|}
\hline $\begin{array}{c}\text { Independent } \\
\text { Variable }\end{array}$ & $\mathrm{x}$ & $S D$ & r-value & P-value \\
\hline $\begin{array}{c}\text { Players } \\
\text { Experience }\end{array}$ & 4.38 & 0.402 & 0.373 & 0.008 \\
\hline \multicolumn{2}{|c|}{ Game Engagement } & 4.38 & 0.402 & \\
\hline
\end{tabular}

$\mathrm{r}=. .373^{* *} \mathrm{p}$-value $=.008$

${ }^{*} p<0.0$ Table 6 above shows the positive correlation between player's experience and game engagement. Since, the $p$-value is $.008<0.05$, then we reject the null hypothesis. There is a significant relationship between players experience and game engagement. This positive correlation implies that when the players' experience increases, the game engagement also increases. On the strength of relationship between variables, with the value of $r=.373$, it has a weak positive relationship. 


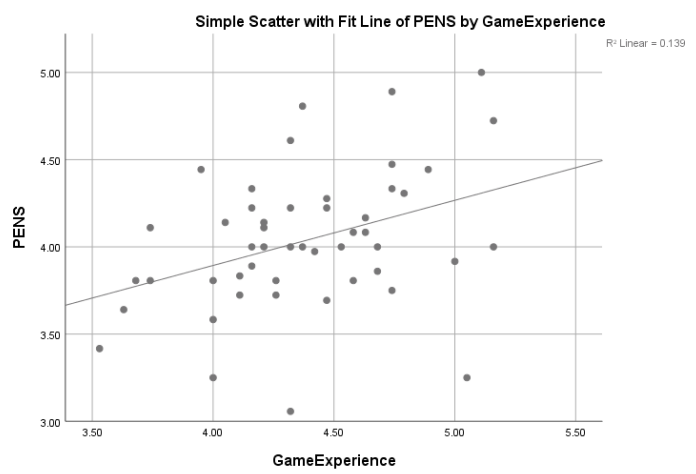

Figure 3: Scatter Plot of Correlations

Therefore, the scatter plots of dots representing the 50 respondents which stand as the scores of each respondent in the independent and dependent variables the dots of observation that near at the linear line serves as the trend of relationship that represents the arrangement of the dot, the line also predicts that the observations have a correlation and that signifies that there is a positive correlation of relationship between the two variables which is the player experience and game engagement of Battle Royale Games Among Gamers in Davao City. There are some dots of observations in the graph. Some of them are bonds, and others are far that are far from the line. They are called outliers [19].

In conjunction with the Wiley handbook of human computer interaction's self-determination theory, gaming applications for objectives such as education, money, and health have garnered significant attention [20]. The creative-relevant talent promotes learning activity through the degree to which the player thinks logically about learning (involvement, concept identification and year of game experience). And it is entirely up to the gamer how he or she participates. The gaming environment serves as the vehicle via which gamers may acquire self-motivation. Games significantly broaden an individual's variety of possible experiences. The gaming environment is the vehicle via which players may acquire self-motivation and substantially broaden their variety of experiences [21].

\section{IV.CONCLUSIONS AND RECOMMENDATIONS}

\section{Conclusions}

The demographic profile of the study's respondents is the first research question. There were 51 people in total: 36 men, 15 women.The majority of respondents are between the ages of 21 and 25, and most gamers around Davao City area.The second research issue concerns the gamers skills in terms of play pattern, game knowledge, and game experience, with a high level of strategy as the overall result. Other things is The length of the game experience, the level of the player Experience among the gamers in Davao City to competence, Autonomy, Relatedness, the level of the game experience in terms of competence, the player experience according to age, gender, Length of game experience, test of significant difference in the level of the game Engagement. The
Instrument has a good level of internal consistency Game Experience Questionnaire (GEQ). The Instrument has an acceptable level of internal consistency.

Thus, various approaches make learners learn effectively as the learners of the game would be given chances to explore new approaches and manifest new responses.

Based on the study and data analysis, Game Engagement helps to better understand how in-game activities influence a player's Engagement in creative activity and learning. Engaging and playing online games make players should be engaging those indicators mentioned above.

Therefore, there is a significant relationship between players experience and game engagement. With this positive correlation,

this implies that when the players experience increases, the game engagement also increases.

\section{Recommendations}

This study has yielded findings that indicate values subscribed by participants manifest that in a certain online game, it creates a positive engagement. The findings concur with and provide practical implications for all who are players who should be more responsible when engaging in a virtual game play. Also to the developers that they should be striving and exhibiting uncertainty, it was surprising to expect to see more impact of gaming experience. These results play a significant role within the game design and development process. However, future studies with more and mature players in each game genre are needed to investigate the definiteness of prior gaming experience.

\section{ACKNOWLEDGEMENT}

For the team work and efforts modulated by various persons to complete this study, the researchers extend the heartfelt thanks and gratitude to all who guided us to the treasure of knowledge. The research team would like to express its deepest gratitude to Father Almighty for giving wisdom, spiritual strength and lighten to guide us to our journey, secondly to our parents for the financial support and morale uplift to continue our study. To our dear adviser, respondents, grammarian, and data analyst everyone who has helped conduct this study, from its days of inception until its fruition thank you so much for the undying support and efforts giving and contributing on this study, the success of the system entitled as Relationship of Player Experience and Game Engagement in Battle Royale Games Among Gamers in Davao City.

\section{REFERENCES}

[1] P. R. M. D. Kenneth, \& C. F. P. Laura, Behavioral addictions: Criteria, evidence, and treatment. United States of America, 2014.

[2] M. Singh, Compulsive digital gaming: An emerging mental health disorder in children. The Indian Journal of Pediatrics, 2019.

[3] S. Mei, Y. H. Yau, J. Chai, J. Guo, \& M. N. Potenza, Problematic Internet use, well-being, self-esteem and self-control: Data from a high-school survey in China. 2016 
[4] World Health Organization. The ICD-10 classification of mental and behavioural disorders: clinical descriptions and diagnostic guidelines. Geneva: World Health Organization. 1992.

[5] P. Satghare, E. Abdin, J. A. Vaingankar, B. Y. Chua, S. Pang, L. Picco, ... Subramaniam, M. Prevalence of sleep problems among those with Internet gaming disorder in Singapore. 2016.

[6] M. Shuttleworth, "Descriptive Research Design - Observing a Phenomenon," 2008.

[7] S. McCombes, "Sampling Methods: Types and Techniques Explained," Scribbr, 23-Apr-2021.

[8] C. Director and Csrm.comms@anu.edu.au, "The Online Panels Benchmarking Study: A Total Survey Error comparison of findings from Probability-based surveys and Non-probability online panel surveys in Australia," 2020.

[9] Narottam Sharma -- Follow, "Quantitative Research Instruments,"

[10] J. R. Evans and A. Mathur, "The value of online surveys: a look back and a look ahead," 2018

[11] H. Taherdoost, "Validity and Reliability of the Research Instrument. 2018

[12] J. R. Evans and A. Mathur, "The value of online surveys: a look back and a look ahead," 2018

[13] Bryman and Bell, "Ethical Considerations - Research Methodology," 2007.

[14] J. A. William, U. Dubey. Measuring Player Experience and Engagement Level in PlayerUnknown's Battlegrounds. 2009

[15] Hartmann, T., Klimmt, C.: Gender and computer games: Exploring females' dislikes. Journal of Computer-Mediated Communication 11, 910-993 (2006)
[16] Sweetser, P., \& Johnson, D. (2004). Player-centered game environments: Assessing player opinions, experiences, and issues. Entertainment Computing-Proceedings from the ICEC.

[17] Habgood, M. J., \& Ainsworth, S. E. (2011). Motivating children to learn effectively: Exploring the value of intrinsic integration in educational games. The Journal of the Learning Sciences, 20, 169206.

[18] Przybylski, A. K., Rigby, C. S., \& Ryan, R. M. (2010). A motivational model of video game engagement. Review of General Psychology, 14(2), 154-166

[19] Inchamnan, W., Wyeth, P., \& Johnson, D. (2013). Does activity in computer game play have an impact on creative behaviour? Proceedings of the Games Innovation Conference (IGIC), 2013 IEEE International.

[20] Ryan, R. M., \& Deci, E. L. (2000). Self-determination theory and the facilitation of intrinsic motivation, social development, and well-being. American psychologist, 55(1), 68-78

[21] Gregorio, C. Elegano, E., Lopez, C., Alejandrino, J., Buladaco, M.V., "Correlation between Online Game Engagement and Attitude towards Online Classes among College Students of Davao del Norte State College", International Journal of Scientific Research and Engineering Development--Volume 4 Issue 1, JanFeb 2021.

[22] Panungcat, J., Vasquez, R., Sabandal, J., Bolacoy, J., Buladaco, M.V., "Strategy Multiplayer Online Battle Arena Game Skills and Learning Behavior: A Correlational Study Among Gamers in Panabo City", International Journal of Scientific Research and Engineering Development--Volume 4 Issue 1, Jan-Feb 2021. 